incapacity will continue to attract a legitimacy which far outweighs their validity. The power of psychiatry will continue as before.

We also disagree with Zigmond's (1998) idea that a Medical Incapacity Act would reduce stigma at a stroke, by offering the same protection to all patients unable to consent to medical interventions. Stigma is primarily a cultural, not a legal, issue. Media representations of mental disorder and distress are currently the greatest problem. Journalists have managed to connect the issues of dangerousness and mental illness in the imagination of both public and politicians and, as a result, tolerance towards people with mental health problems is at an all time low. This can only be combatted by a joint campaign of users and professionals. In turn, this will only happen if professionals begin to question the politics of mental health and the limitations of their knowledge in an open way. If psychiatrists continue to assert a simple equation between bodily and mental illness they will miss an historic opportunity to open up a new agenda in the area of mental health.

FULFORD, K. M. (1998) Invited commentaries on: Mental health legislation is now a harmful anachronism. Psychiatric Bulletin, 22, 666-668.

Zigmond, A. S. (1998) Medical Incapacity Act. Psychiatric Bulletin. 22, 657-658.

P. BRACKEN, Consultant Psychiatrist and PHILIP THOMAS, Bradford Home Treatment Service, Edmund Street Clinic, 26 Edmund Street, Bradford BD5 OBJ

\section{Mental incapacity}

Sir: Szmukler \& Holloway (Psychiatric Bulletin, December 1998; 22, 662-665) are misguided to suggest that incapacitated patients would be afforded better protection by the adoption of an Incapacity Act along the lines proposed by the Government Green Paper Who Decides (Lord Chancellor's Department, 1997).

The Green Paper gives no guidance as to how, or by whom, incapacity is to be judged and takes no account of 'shades' of capacity or temporary incapacity. Once patients are designated as 'incapacitated', a previously drafted 'living will' may come into force which requires 'treatment', possibly including food and fluids, to be withdrawn, leading to death by dehydration or starvation. Gardner et al (1985) showed that patients change their minds when illness strikes them; however, it would be hard for patients to change or withdraw advance directives if they had already been classified as incapacitated. Moreover, suicide notes may under this legislation constitute advance statements. Cries for help could become death warrants. The Bill also makes legal non-consensual medical procedures (Clause 10) and research (Clause 11) on incapacitated' patients, even if of no benefit to them. This could include organ removal from a non-dying patient.

Doctors attempting to resist any of the possibilities discussed could be liable to criminal prosecution. Rather than providing the extra protection to mentally incapacitated people which Szmukler \& Holloway so laudably seek, this Bill would make possible widespread abuse of these patients and lead to a fatal compromise in medical ethics. Our profession should therefore resist it at all costs.

GARDNER. B. P.. Theocleous, F., WATt, J. W. H. et al (1985) Ventilation or dignifled death for patients with high tetraplegia. British Medical Journal, 291, 1620-1622.

LORD ChANCELLOR'S DEPARTMENT (1997) Who Decides? Making Decisions on Behalf of Mentally Incapacitated Adults. London: HMSO.

DAVID KINGSLEY, Basic Specialist Trainee in Old Age Psychiatry. West Lancashire NHS Trust. Ormskirk, Lancashire L39 2AZ

\section{Participation in continuing professional development}

Sir: Contrary to Weaver's assertion (Psychiatric Bulletin, December 1998, 22, 771), my editorial (Psychiatric Bulletin, September 1998, 22, 529530) did not speculate in any way on the continuing professional development (CPD) activities of psychiatrists who have not registered with our College-based scheme. I regret that Weaver seems to have missed the crucial point of my article, which set out to emphasise how important it is that our CPD scheme should be given all possible support. Participation in CPD is only part of what is expected of us. We also need to demonstrate clearly that we have done so. Our scheme is surely the best way to coordinate this process and ultimately demonstrate its effectiveness.

As I predicted, things have now moved apace and some form of revalidation is a near certainty. I can only guess at what this will entail, but I do believe that a well supported College-based scheme should offer psychiatrists several distinct benefits. It is conceivable that Collegebased CPD credentials might be taken into account in the revalidation process, and they should help to maintain a standard of excellence which is set nationally. A recent survey of attitudes to our scheme has shown that among a sample of consultants who have not registered for CPD, the most common reason for not doing so is an excessive clinical work load. Here too a College based scheme should be well placed to challenge relevant employing NHS trusts in a 
way that would be impossible in any alternative that is entirely trust organised. Our scheme should also help psychiatrists to retain an overall identity by reminding us that we all share certain basic clinical skills, whatever our speciality within it. It should also help us to retain a say in what we do and what we stand for at a time when others may be only too willing to make these decisions for us.

H. G. MORGan, Emeritus Professor of Mental Health, University of Bristol, Division of Psychiatry, 41 St Michael's Hill, Bristol BS2 8DZ

\section{Are inappropriate admissions a problem?}

Sir: Elwood's (Psychiatric Bulletin, January $1999,23,37-40)$ study of inappropriate admissions suggests junior doctors can recognise when acute in-patient care is not the most appropriate treatment. Despite this, $24 \%$ of all admissions were deemed inappropriate, with the 'ideal' alternative ranging from social service referral to in-patient rehabilitation.

Occupancy rates are often much higher in England and Wales (Ford et al, 1998) than the recommended $85 \%$ (Royal College of Psychiatrists, 1988), making it desirable for patients who do not require acute in-patient care to be diverted to an appropriate alternative or to be discharged from hospital rapidly. As inappropriate admissions occupied only $3 \%$ of all acute inpatient beds in Elwood's study, diversion to more appropriate care, even if it were possible, might have only modest effects on occupancy rates. A much larger problem contributing to high occupancy rates are patients who, while admitted appropriately, have recovered sufficiently to be discharged. In a recent cross-sectional audit of 89 acute in-patients in Tower Hamlets, $23 \%$ were considered by their keyworker as no longer requiring treatment on an acute ward, and of these $25 \%$ were still in-patients three months later.

Focusing on all patients who do not require inpatient care, rather than only those for whom admission may not have been the ideal intervention is probably a better use of audit resources. In practice, however, inappropriate admissions may contribute to high occupancy levels both by occupying beds and diverting staff time from the review of settled patients who no longer require admission.

FORD, R., DURCAN, G., WARNer, L., et al (1998) One-day survey by the Mental Health Act Commission of acute adult in-patient wards in England and Wales. British Medical Journal, 317. 1279-1283.
Royal College of Psychiatrists (1988) Psychiatric Beds and Resources: Factors Influencing Bed Use and Service Planning. Report of a Working Party of the Section for Social and Community Psychiatry of the Royal College of Psychiatrists. London: Gaskell.

RICHARD DUFFETT, Specialist Registrar in General Psychiatry. St Clement's Hospital, 20 Bow Road. London E3 $4 L L$

\section{Anticholinergic treatment}

Sir: We would like to compliment the excellent report on anticholinergic treatment by Williams (Psychiatric Bulletin, January 1999, 23, 22-24). We would like to add a few points about the use of these medications.

Anticholinergic drugs are often considered as 'side-effect medication' by many patients as well as some clinicians. Hence, they are often prescribed inappropriately, unaware of the fact that they can worsen anticholinergic side-effects including dry mouth, dry eyes, dry flushed skin. dilated pupils and blurring of vision. Anticholinergic drugs help relieve tremor and rigidity, but bradykinesia is less likely to be helped. Extrapyramidal side-effects are not manifested during sleep. Hence, a bedtime dose is unnecessary. Moreover, its stimulant effect can impair sleep. Anticholinergic drugs are ineffective in the prevention and treatment of akathisia and neuroleptic malignant syndrome. Anticholinergic drugs not only increase the risk of developing tardive dyskinesia, but also worsen existing tardive dyskinesia.

Anticholinergic drugs can cause psychological dependence. The street value of procyclidine is about $\& 1$. This may partly explain why some patients feign extrapyramidal symptoms to get a continued and/or increased prescription of these drugs.

K. S. GRacious, Senior House Officer in Psychiatry, Priority Care NHS Trust Hospital, Maidstone ME16 9QQ: S. HOPTON, E. SCHIMPF, A. PRASEEDOM, Senior House Officers in Psychiatry, West Suffolk Hospital, Bury St Edmunds IP33 2QZ

\section{Recent audit of people taking lithium}

Sir: We were interested to read Anderson \& Sowerbutt's paper (Psychiatric Bulletin, December $1998,22,740-743)$. We recently carried out an audit of people on lithium ( $n=27$, age range 66-98 years, mean 79.8) under the care of one old age psychiatrist. Fifty-five per cent had unipolar/psychotic depression, $30 \%$ had a bipolar affective disorder and $15 \%$ had a schizoaffective illness. Eleven had lithium for more than five years. Each person (or carer if the carer was 